\title{
Regulation of Ventral Surface Chemoreceptors by the Central Respiratory Pattern Generator
}

\author{
Patrice G. Guyenet, Daniel K. Mulkey, Ruth L. Stornetta, and Douglas A. Bayliss \\ Department of Pharmacology, University of Virginia, Charlottesville, Virginia 22908
}

The rat retrotrapezoid nucleus (RTN) contains neurons described as central chemoreceptors in the adult and respiratory rhythmgenerating pacemakers in neonates [parafacial respiratory group (pfRG)]. Here we test the hypothesis that both RTN and pfRG neurons are intrinsically chemosensitive and tonically firing neurons whose respiratory rhythmicity is caused by a synaptic feedback from the central respiratory pattern generator (CPG). In halothane-anesthetized adults, RTN neurons were silent below $4.5 \%$ end-expiratory (e-exp) $\mathrm{CO}_{2}$. Their activity increased linearly $\left(3.2 \mathrm{~Hz} / 1 \% \mathrm{CO}_{2}\right)$ up to $6.5 \%$ (CPG threshold) and then more slowly to peak $\sim 10 \mathrm{~Hz}$ at $10 \%$ $\mathrm{CO}_{2}$. Respiratory modulation of RTN neurons was absent below CPG threshold, gradually stronger beyond, and, like pfRG neurons, typically (42\%) characterized by twin periods of reduced activity near phrenic inspiration. After CPG inactivation with kynurenate (KYN), RTN neurons discharged linearly as a function of e-exp $\mathrm{CO}_{2}$ (slope, $+1.7 \mathrm{~Hz} / 1 \% \mathrm{CO}_{2}$ ) and arterial pH (threshold, 7.48; slope, $39 \mathrm{~Hz} / \mathrm{pH}$ unit). In coronal brain slices (postnatal days 7-12), RTN chemosensitive neurons were silent at pH 7.55. Their activity increased linearly with acidification up to $\mathrm{pH} 7.2\left(17 \mathrm{~Hz} / \mathrm{pH}\right.$ unit at $\left.35^{\circ} \mathrm{C}\right)$ and was always tonic.

In conclusion, consistent with their postulated central chemoreceptor role, RTN/pfRG neurons encode pH linearly and discharge tonically when disconnected from the rest of the respiratory centers in vivo (KYN treatment) and in vitro. In vivo, RTN neurons receive respiratory synchronous inhibitory inputs that may serve as feedback and impart these neurons with their characteristic respiratory modulation.

Key words: central chemoreceptors; medulla oblongata; ventral medullary surface; parafacial respiratory group; dendritic structure; respiratory modulation

\section{Introduction}

Breathing relies on a rhythmically active network of brainstem neurons that is driven by central chemoreceptors and other sources of tonic excitatory drive (Feldman et al., 2003). Most of this network is located within the ventral respiratory column (VRC) (Alheid et al., 2002), the most rostral aspect of which is called retrotrapezoid nucleus (RTN) in the adult (Connelly et al., 1989; Smith et al., 1989; Cream et al., 2002; Feldman et al., 2003) and parafacial respiratory group (pfRG) in the neonate rat (Onimaru and Homma, 2003). RTN/pfRG provides a major excitatory drive to the central respiratory pattern generator (CPG) (Fukuda et al., 1993; Nattie and Li, 2000; Feldman et al., 2003; Onimaru and Homma, 2003), but its functional role within the respiratory network remains unclear. The phasic and often preinspiratory discharge pattern of pfRG neurons in neonate preparations supports a pacemaker neuron-based inspiratory or expiratory rhythmogenic role for pfRG (Onimaru et al., 1995; Takeda et al., 2001; Janczewski et al., 2002; Onimaru and Homma, 2003), whereas the more tonic discharge of adult RTN

Received June 13, 2005; revised July 28, 2005; accepted Aug. 16, 2005.

This research was supported by National Institutes of Health Grants HL 74011 and HL 28785 (P.G.G.).

Correspondence should be addressed to Dr. Patrice G. Guyenet, University of Virginia Health System, P.0. Box 800735, 1300 Jefferson Park Avenue, Charlottesville, VA 22908-0735. E-mail: pgg@virginia.edu. DOI:10.1523/JNEUROSCI.2415-05.2005

Copyright $\odot 2005$ Society for Neuroscience $\quad$ 0270-6474/05/258938-10\$15.00/0 neurons in vivo favors a central chemoreceptor function (Li and Nattie, 2002; Mulkey et al., 2004; Putnam et al., 2004).

The present study tests a unified theory of the role of RTN/ pfRG. We propose that RTN and pfRG neurons are essentially the same neurons, that these cells, in vitro and under anesthesia in vivo, derive most of their activity from their intrinsic chemosensitivity, and that their respiratory rhythmicity is attributable to inhibitory synaptic inputs from the CPG not to intrinsic bursting properties. In essence, we hypothesize that the CPG input to the chemosensitive neurons of RTN/pfRG is a simple feedback. This feedback originates from phasically active respiratory neurons and therefore produces the respiratory modulation of RTN/pfRG previously observed under various experimental conditions (Connelly et al., 1990; Nattie et al., 1993; Onimaru et al., 1995; Bodineau et al., 2000; Takeda et al., 2001; Janczewski et al., 2002; Onimaru and Homma, 2003).

To test this theory, the CPG inputs to RTN neurons were examined in anesthetized rats by means of perievent histograms of unit activity triggered on the phrenic discharge (PND). The presumed intrinsic response of $\mathrm{RTN}$ to $\mathrm{pH}$ was examined in the same preparation after pharmacological blockade of the CPG and in vitro using coronal slices in which connections between $\mathrm{CPG}$ and RTN are severed.

In support of the proposed theory, we found that RTN neurons receive inhibitory inputs from the CPG whose intensity increases with $\mathrm{pCO}_{2}$ in vivo and causes their firing rate to saturate at 
a

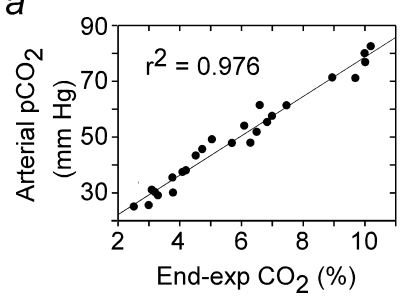

$b$

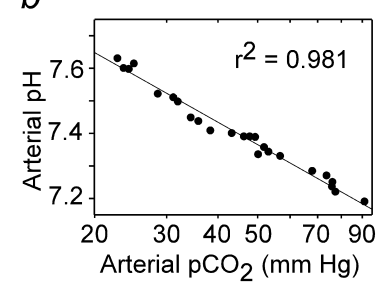

c

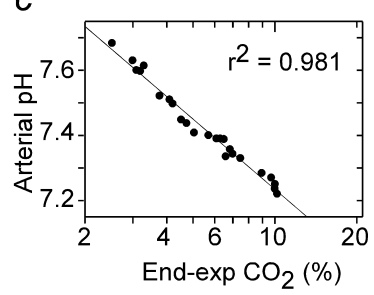

arterial $\mathrm{pCO}_{2}$ on a semilog scale (Fig. $1 b$ ). Thus, arterial $\mathrm{pH}$ was also a linear function of e-exp $\mathrm{CO}_{2}$ expressed on a semilog scale (Fig. 1c). This relationship was represented by the following equation: $\mathrm{pHa}=7.955-0.7215 \times \log _{10}$ (e-exp $\mathrm{CO}_{2}$ ), which could thus be used to convert the end-expiratory $\mathrm{CO}_{2}$ data points into arterial $\mathrm{pH}$ (pHa) values. This approach allowed us to determine the relationship between the discharge rate of several RTN neurons and arterial $\mathrm{pH}$ in a given rat based on the capnometer readings without need for frequent and disruptive blood sampling.

In vivo recordings of physiological parameters and neuronal activity. BP and mass PND were recorded conventionally, the latter with bipolar

high levels of $\mathrm{pCO}_{2}$. We also found that $>40 \%$ of RTN neurons have two periods of reduced activity per respiratory cycle in a pattern reminiscent of neonate pfRG neurons. However, after CPG blockade, RTN neurons respond linearly to $\mathrm{pCO}_{2}$ or $\mathrm{pH}$ as they do in slices when exposed to the same $\mathrm{pH}$ range and their firing becomes tonic. The results suggest that RTN neurons are central chemoreceptors whose respiratory modulation and curvilinear relationship to arterial $\mathrm{pH}$ in vivo is attributable to a feedback from the CPG.

\section{Materials and Methods}

The experiments were performed in 30 male Sprague Dawley rats (Taconic Farms, Germantown, NY) weighing 250-350 g. Procedures were in accordance with National Institute of Health Animal Care and Use Guidelines and were approved by the Animal Care and Use Committee of the University of Virginia. Seven rats were vagotomized, the rest were not. Among the latter group, eight received kynurenic acid.

Surgery and anesthesia. General anesthesia was induced with 5\% halothane in $100 \%$ oxygen. The rats were subjected to a tracheotomy, and artificial ventilation with $1.7-1.8 \%$ halothane in $100 \%$ oxygen was maintained throughout surgery. All rats were subjected to the following previously described surgical procedures: brachial or femoral artery cannulation for blood pressure (BP) measurement, jugular or femoral vein cannulation for administration of fluids and drugs, removal of the occipital plate to insert a recording electrode into the medulla oblongata via a dorsal transcerebellar approach, and skin incision over the lower jaw for placement of a bipolar stimulating electrode next to the mandibular branch of the facial nerve (Brown and Guyenet, 1985). The phrenic nerve was accessed by a dorsolateral approach after retraction of the right shoulder blade. A bilateral vagotomy in the neck was performed in seven rats.

For the duration of the recording period (2.5-4.5 h), the halothane concentration was reduced to $0.9-1 \%$ (calibrated vaporizer). All rats were ventilated with $100 \%$ oxygen throughout the experiment. Under hyperoxic conditions, and especially in the presence of halothane, peripheral chemoreceptors contribute very little, if at all, to the activation of the CPG or RTN neurons by hypercapnia (Fitzgerald and Lahiri, 1991; Mulkey et al., 2004). The adequacy of the anesthesia was gauged by the fact that nociceptive stimuli applied to the tail and hind legs failed to increase BP and PND rate or amplitude. The same criteria were applied after the muscle relaxant pancuronium was administered at the initial dose of $1 \mathrm{mg} / \mathrm{kg}$ intravenously.

Blood gases were measured at steady state at the end of 4 min exposures to various steady levels of $\mathrm{CO}_{2}$ in the breathing mixture. These measurements were made using an I-STAT portable clinical analyzer and CG8+ cartridges (Heska, Waukesha, WI) in three halothaneanesthetized, paralyzed rats that had received no other drug and in three similarly prepared rats that had received kynurenate (KYN) intracerebroventricularly within the previous $2 \mathrm{~h}$. The relationship between arterial $\mathrm{pH}$ and arterial $\mathrm{pCO}_{2}$ was the same in each group, and the results were pooled. Arterial $\mathrm{pCO}_{2}$ determined by blood gas analysis and endexpiratory (e-exp) $\mathrm{CO}_{2}$ measured with the capnometer were highly linearly correlated (Fig. 1a). As expected, arterial $\mathrm{pH}$ was a linear function of electrodes (Koshiya and Guyenet, 1996). Tracheal $\mathrm{CO}_{2}$ was analyzed on-line by a Micro-Capnometer designed for rodents (Columbus Instruments, Columbus, $\mathrm{OH}$ ) and calibrated twice per experiment against a calibrated $\mathrm{CO}_{2} / \mathrm{N} 2$ mix. This instrument provided a reading of $<0.1 \%$ $\mathrm{CO}_{2}$ during inspiration in animals breathing $100 \%$ oxygen and an asymptotic, nearly horizontal reading during expiration.

Before searching for cells, ventilation was adjusted to lower endexpiratory $\mathrm{CO}_{2}$ to $4 \%$ at steady state $(60-80 \mathrm{cycles} / \mathrm{s}$; tidal volume, $1.2-$ $1.4 \mathrm{ml} / 100 \mathrm{~g}$ ). These conditions were selected because $4 \%$ end-expiratory $\mathrm{CO}_{2}$ was typically below the firing threshold of both RTN units and the PND. Variable amounts of pure $\mathrm{CO}_{2}$ were then added to the breathing mixture to adjust end-expiratory $\mathrm{CO}_{2}$ to the desired level. When searching for RTN units, end-expiratory $\mathrm{CO}_{2}$ was set $\sim 7 \%$ to ensure that PND and the $\mathrm{CO}_{2}$-sensitive neurons of RTN were active.

All recording and electrophysiological methods have been described previously (Mulkey et al., 2004). Unit recordings were made with glass electrodes filled with unbuffered $0.5 \mathrm{M}$ sodium acetate occasionally containing biotinamide for juxtacellular labeling (direct current resistance before insertion into brain, 18-24 M $\Omega$ ). All analog data (end-expiratory $\mathrm{CO}_{2}$, $\mathrm{PND}$, unit, $\mathrm{BP}$, and stimulation pulses) were stored on a microcomputer via a micro-1401 digitizer from Cambridge Electronics Design (Cambridge, UK) and were processed off-line using version 5 of the Spike 2 software (Cambridge Electronics Design). Processing included action potential discrimination and binning, neuronal discharge rate measurement, and PND "integration" (iPND) consisting of rectification and smoothing ( $\tau$ of $0.015 \mathrm{~s}$ ). Neural minute $\times$ volume [mvPND (a measure of the total phrenic nerve discharge per unit of time)] was determined by averaging iPND over 20 CPG cycles and normalizing the result by assigning a value of 0 to the dependent variable recorded at low levels of endexpiratory $\mathrm{CO}_{2}$ (below threshold) and a value of 1 at the highest level of $\mathrm{pCO}_{2}$ investigated (between 9.5 and 10\%). The Cambridge Electronics Design program was also used for acquisition of perievent histograms of neuronal activity and perievent averages of iPND or tracheal $\mathrm{CO}_{2}(\mathrm{Ko}-$ shiya and Guyenet, 1996). The perievent histograms of neuronal singleunit activity were triggered on either iPND or the tracheal $\mathrm{CO}_{2}$ trace and represented the summation of between 100 and 200 respiratory cycles (500-2000 action potentials per histogram). The steady-state relationship between RTN neuronal activity and end-expiratory $\mathrm{CO}_{2}$ was obtained by stepping the inspired $\mathrm{CO}_{2}$ level to various values for a minimum of $2 \mathrm{~min}$ and up to $4 \mathrm{~min}$. The mean discharge rate of the neuron was measured during the last $30 \mathrm{~s}$ of each step, at which time endexpiratory $\mathrm{CO}_{2}$ and the discharge of the neuron appeared to have reached equilibrium. End-expiratory $\mathrm{CO}_{2}$ was measured by averaging the maximum values recorded from 10 consecutive breaths at the midpoint of the time interval sampled.

As in previous work (Mulkey et al., 2004), the caudal and ventral boundaries of the facial motor nucleus were identified in each rat by the large (up to $5 \mathrm{mV}$ ) negative antidromic field potential generated in the facial motor nucleus by stimulating the mandibular branch of the facial nerve (Fig. 2a) (for details, see Brown and Guyenet, 1985). $\mathrm{CO}_{2}$-activated neurons were encountered between 200 and $350 \mu \mathrm{m}$ below the lower edge of the facial motor nucleus, $1.6-1.9 \mathrm{~mm}$ lateral to the midline, and from $100 \mu \mathrm{m}$ caudal to $400 \mu \mathrm{m}$ rostral to the caudal end of the facial field 
potential. Previous single neuron labeling experiments have indicated that this region lies between coronal planes bregma $-11.6 \mathrm{~mm}$ and bregma $-11.2 \mathrm{~mm}$ of the Paxinos and Watson (1998) atlas and matches previous definition of the RTN (Cream et al., 2002; Mulkey et al., 2004). The medullary region located lateral and rostral to RTN, i.e., situated under the lateral half of the facial motor nucleus, was also systematically explored in a grid-like pattern, but it did not contain any recordable neuron. Most recordings were made on the left side of the brain. The RTN also contains presympathetic barosensitive neurons located on average 200 $\mu \mathrm{m}$ dorsal to the $\mathrm{CO}_{2}$-sensitive neurons (Mulkey et al., 2004). These cells have little or no sensitivity to $\mathrm{CO}_{2}$ under the chosen experimental conditions and were ignored in the present study.

KYN (Sigma, St. Louis, MO) was prepared as a $0.5 \mathrm{M}, \mathrm{pH} 7.3$ stock solution and, before use, diluted 50\% with normal bicarbonate Ringer's solution of the following composition (in $\mathrm{mm}$ ): $130 \mathrm{NaCl}, 3 \mathrm{KCl}, 2 \mathrm{MgCl}_{2}, 2 \mathrm{CaCl}_{2}, 1.25$ $\mathrm{NaH}_{2} \mathrm{PO}_{4}, 26 \mathrm{NaHCO}_{3}$, and 10 glucose. The solution was slowly injected (2-4 min; 50-60 $\mu l)$ into the CSF via a needle inserted through the atlanto-occipital membrane. The needle shaft had been sealed to the membrane with superglue before performing the injection. KYN injected in this manner bathes the lower brainstem and spinal cord, causing an initial increase followed by a sustained drop in blood pressure (Sun et al., 1988). KYN also eliminates PND and the cyclic respiratory discharge of neurons within the ventrolateral medulla (Mulkey et al., 2004).

Statistical analysis was done with Sigma Stat version 1.0 (Jandel Scientific, Corte Madera, CA). Data are reported as means \pm SE. $t$ test, paired $t$ test, and one-way parametric ANOVA followed by the Newman-Keuls multiple comparisons test were used as appropriate. Significance was set at $p<0.05$.

Recordings in slices. Loose-patch currentclamp recordings of RTN neurons were done in $300-\mu \mathrm{m}$-thick coronal slices of the rat medulla oblongata as described previously. Briefly, slices were prepared from neonatal rats [postnatal day 7 (P7) to P12] that typically received an intraperitoneal injection of Fluoro-Gold (FG) (15 mg/kg; Fluorochrome, Denver, CO) 1-2 d before the animals were killed. FG is a fluorescent dye that is excluded from the CNS but labels brainstem motor neurons by retrograde transport from their peripheral axons (Leong and Ling, 1990). Animals were decapitated under ketamine/xylazine anesthesia, and transverse slices $(300 \mu \mathrm{m})$ were prepared from brainstem using a microslicer (DSK 1500E; Dosaka, Kyoto, Japan) in ice-cold substituted Ringer's solution containing the following (in mM): 260 sucrose, $3 \mathrm{KCl}, 5 \mathrm{MgCl}_{2}, 1 \mathrm{CaCl}_{2}, 1.25 \mathrm{NaH}_{2} \mathrm{PO}_{4}, 26$ $\mathrm{NaHCO}_{3}, 10$ glucose, and 1 kynurenic acid. Slices were incubated for $\sim 30 \mathrm{~min}$ at $37^{\circ} \mathrm{C}$ and subsequently at room temperature in normal Ringer's solution containing the following (in $\mathrm{mm}$ ): $130 \mathrm{NaCl}, 3 \mathrm{KCl}, 2 \mathrm{MgCl}_{2}$, $2 \mathrm{CaCl}_{2}, 1.25 \mathrm{NaH}_{2} \mathrm{PO}_{4}, 26 \mathrm{NaHCO}_{3}$, and 10 glucose. Both substituted and normal Ringer's solutions were bubbled with $95 \% \mathrm{O}_{2} / 5 \% \mathrm{CO}_{2}$. Slices were submerged in a chamber mounted on a fixed-stage microscope (Axioskop FS; Zeiss, Oberkochen, Germany), and neurons were visualized using Nomarski optics and identified by location in the slice. Recordings were made from neurons located within $200 \mu \mathrm{m}$ of the venend-expiratory $\mathrm{CO}_{2}$. $b$

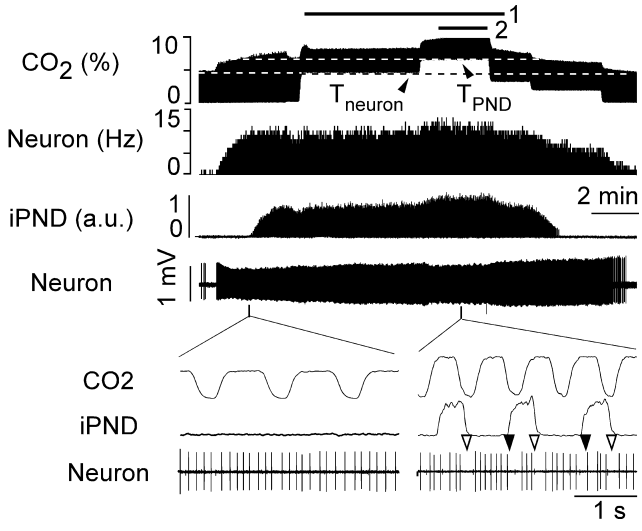

$d$
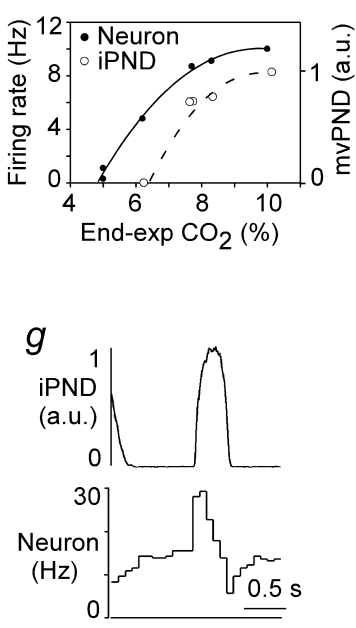

Figure 2. Response of one RTN chemosensitive neuron to hypercapnia in a vagotomized rat. $\boldsymbol{a}$, Experimental system. Single added to the breathing mixture as indicated by the step changes in end-expiratory $\mathrm{CO}_{2}$ (top trace). Bottom traces represent from p to bottom the discharge rate of the neuron (integrated rate histogram), the PND rectified and smoothed (PND), and the (he dhe central respiratory modulation of the neuron at high levels of $\mathrm{CO}_{2}$ Perievent histograms of the neuronal discharge triggered on the ventilation cycle (left, period corresponding to bar 1 in $\boldsymbol{a}$ ) or iPND (right, period corresponding to bar 2 in $\boldsymbol{a}$ ). $\boldsymbol{d}$, Steady-state relationship between neuronal firing rate or mvPND [neural minute $X$ volume in arbitrary units (a.u.)] and end-expiratory $\mathrm{CO}_{2}$ at steady state. Note the curvilinear aspect of both plots and the fact that to bottom, tracheal $\mathrm{CO}_{2}$ in percentage, iPND, and extracellular action potentials). $\boldsymbol{f}$, PND-triggered activity histogram of neuron shown in e recorded at $7 \%$ end-expiratory $\mathrm{CO}_{2} . \boldsymbol{g}$, PND-triggered activity histogram of neuron shown in $\boldsymbol{e}$ recorded at $9.5 \%$

tral surface and below the caudal end of the facial motor nucleus predominantly but not exclusively under the medial half of the nucleus. The facial motor nucleus was identified by the presence of FG.

Loose-patch recordings were obtained at room temperature $\left(23^{\circ} \mathrm{C}\right)$ and/or at $35^{\circ} \mathrm{C}$ using $3-5 \mathrm{M} \Omega$ patch pipettes and an Axopatch $200 \mathrm{~B}$ amplifier (Axon Instruments, Union City, CA). In RTN neurons, we found no difference in the firing response to changes in $\mathrm{pH}$ under wholecell and loose-patch configurations (data not shown). Nevertheless, to avoid any potential problems with washout of $\mathrm{pH}$ sensitivity (Richerson, 1995), all of the data presented in Results relate to $\mathrm{pH}$ sensitivity determined in the loose-patch configuration. The bath solution was perfused continuously $(\sim 2 \mathrm{ml} / \mathrm{min}$ ) and was composed of the following (in $\mathrm{mM}$ ): $140 \mathrm{NaCl}, 3 \mathrm{KCl}, 2 \mathrm{MgCl}_{2}, 2 \mathrm{CaCl}_{2}, 10$ HEPES, and 10 glucose; the $\mathrm{pH}$ of the bath solution was adjusted by addition of $\mathrm{HCl}$ or $\mathrm{NaOH}$. Internal solution contained the following: $120 \mathrm{~mm} \mathrm{KCH}_{3} \mathrm{SO}_{3}, 4 \mathrm{mM} \mathrm{NaCl}_{2}, 1 \mathrm{~mm}$ 
a

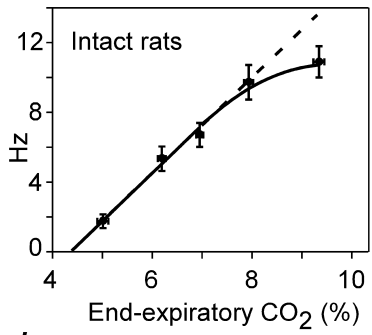

$d$

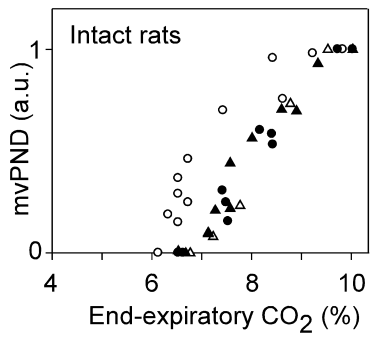

$b$

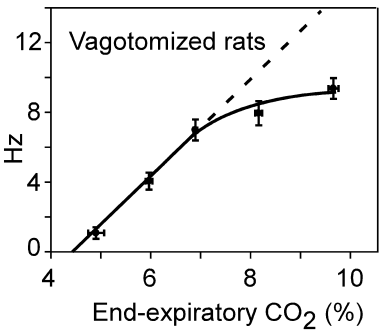

e

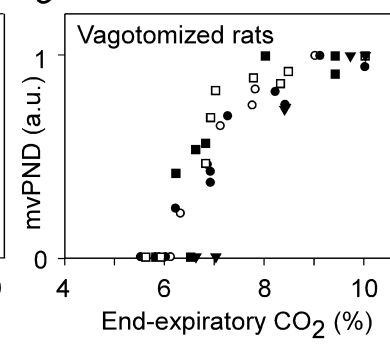

c

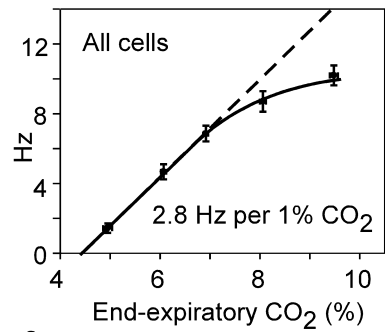

$f$

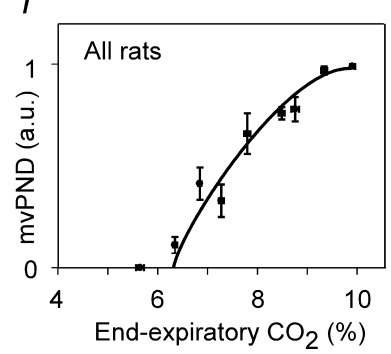

Figure 3. Effect of $\mathrm{CO}_{2}$ on PND and RTN neuron activity at steady state: group data. $\boldsymbol{a}$, Averaged firing rate of nine cells in seven rats with intact vagus nerves. The data points from all cells were regrouped into five bins according to the $\mathrm{CO}_{2}$ level at which each determination was made $(<5.5,5-5-6.5,6.5-7.5,7.5-8.5,>8.5 \%)$, and the values were averaged within these bins (mean \pm SE shown for both axis). In this and the next two panels, the dotted and solid lines were traced by hand only to emphasize the divergence from linearity at high levels of e-exp $\mathrm{CO}_{2}$ levels. $\boldsymbol{b}$, Averaged firing rate of 13 cells in four vagotomized rats (data processed as in $\boldsymbol{a}$ ). $\boldsymbol{c}$, Averaged firing rate of all 22 cells. $\boldsymbol{d}$, Relationship between mvPND and e-exp $\mathrm{CO}_{2}$ at steady state in five intact rats. $\boldsymbol{e}$, Relationship between mvPND and e-exp $\mathrm{CO}_{2}$ at steady state in five vagotomized rats. $\boldsymbol{f}$, Relationship between mvPND and $\mathrm{CO}_{2}$ at steady state (pooled data from 5 intact and 5 vagotomized rats). a.u., Arbitrary units.

a1

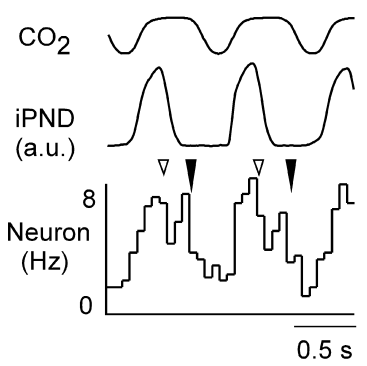

b1

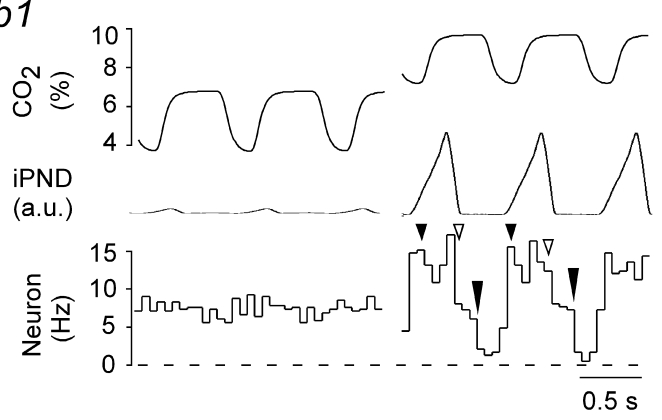

a2

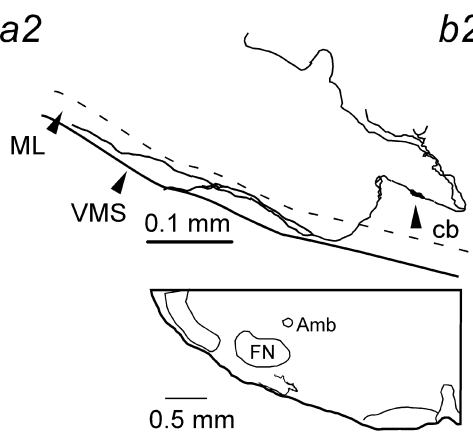

$b 2$

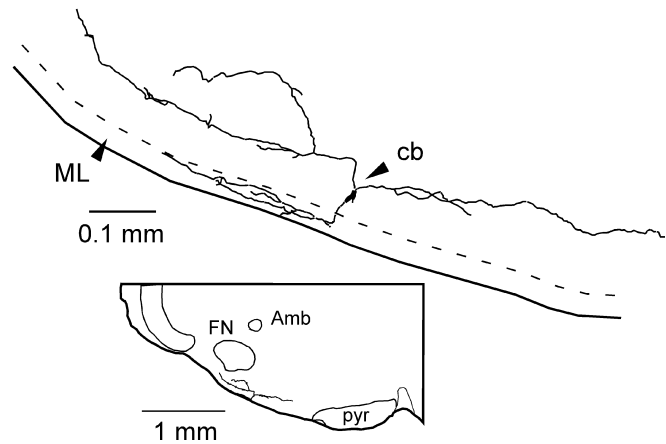

Figure 4. Structure of RTN neurons. a1, PND-triggered activity histogram of a $\mathrm{CO}_{2}$-sensitive RTN neuron in a rat with intact vagus nerves. Note that tracheal $\mathrm{CO}_{2}$ and PND are synchronized. The open arrow points to the beginning of the post-inspiratory phase; the long filled arrow indicates the start of the late-expiratory phase (E2). a2, Structure of the neuron shown in $\boldsymbol{a 1}$. Note the extensive dendrites within the marginal layer (ML) of the ventral medullary surface (VMS). Cb, Cell body; Amb, nucleus ambiguus; FN, facial motor nucleus. $\boldsymbol{b 1}, \boldsymbol{b} 2$, Discharge pattern and structure of a different RTN neuron recorded in a different vagotomized rat. The small filled arrow indicates the onset of PND. The other arrows have the same meaning as in a1. a.u., Arbitrary units.

$\mathrm{MgCl}_{2}, 0.5 \mathrm{~mm} \mathrm{CaCl}_{2}$, 10 mu HEPES, 10 mm EGTA, 3 mм Mg-ATP, 0.3 $\mathrm{mm}$ GTP-Tris, and $0.2 \%$ biocytin, $\mathrm{pH}$ 7.2. All chemicals were from Sigma. Membrane potential and current were recorded and analyzed using a Digidata 1320A digitizer and either pClamp (Axon Instruments) or Spike2 (Cambridge Electronics Design). All data are expressed as means \pm SEM; statistical tests included one-way ANOVA and NewmanKeuls multiple comparison test or paired Student's $t$ test, as indicated, with a significance level of $p<0.05$.

\section{Results}

Effect of $\mathrm{CO}_{2}$ on PND and RTN neuron activity under steady-state conditions

Rats were exposed to long-lasting (3-4 min) stepwise changes in e-exp $\mathrm{CO}_{2}$ to determine the relationship between $\mathrm{CO}_{2}$ and RTN neuronal discharge or PND at steady-state. The neuron shown in Figure $2 b$ is representative of experiments performed in 13 cells from four vagotomized rats. The neuron had a threshold $\sim 4.5 \%$ $\mathrm{CO}_{2}$, considerably below the PND threshold (Fig. 2b,d). The inserts at the bottom of $b$ illustrate the regularity of the discharge below PND threshold and the respiratory modulation observable above this threshold. Figure $1 c$ depicts two types of perievent activity histograms for the same neuron. The first one derived from period 1 in $b$ is triggered by the ventilation cycle. This perievent histogram is flat, indicating that the cell was entrained by neither ventilation-related brain pulsations nor sensory afferents with activity synchronized with ventilation. The second perievent histogram (Fig. $2 c$, period 2) was triggered by iPND during the period indicated in $b$. The averaged $\mathrm{CO}_{2}$ trace is flat because the $\mathrm{PND}$ is free-running relative to the ventilation cycle (e-exp $\mathrm{CO}_{2}$ ), a consequence of the double vagotomy (see also excerpts in Fig. 2b). The PND-triggered histogram of the neuron displayed two periods of reduced activity coinciding, respectively, with the early-inspiratory (early-I) and the post-inspiratory (post-I) phases of the CPG (Fig. 2c). The relationship between the firing rate of the neuron and end-expiratory $\mathrm{CO}_{2}$ was approximately linear at low levels of $\mathrm{CO}_{2}$ and displayed a marked degree of saturation at higher levels of $\mathrm{CO}_{2}$ (Fig. 2b,d). The mvPND (neural minute $\times$ volume) was also a curvilinear function of $\mathrm{CO}_{2}$ (Fig. 2d). The other $\mathrm{CO}_{2}$-sensitive neurons of RTN had similar characteristics $\left(\mathrm{pCO}_{2}\right.$ threshold between 4 and 5\%, curvilinear relationship to $\mathrm{pCO}_{2}$ ). The lack of respiratory modulation below PND threshold and the increase of the modulation approximately in proportion with PND amplitude was a universal finding (Fig. 1f,g), but the pattern of their respiratory modulation varied from cell to cell within the same animal (Fig. 2e,f). At the population level (Fig. 3), the discharge of RTN neurons was a linear function of e-exp $\mathrm{CO}_{2}$ from a threshold of $4.5 \%$ on average to the $\mathrm{CO}_{2}$ level correspond- 
ing to the PND threshold $(6.5 \%$ on average). The linear part of the curve had a slope of $2.8 \mathrm{~Hz} / 1 \% \mathrm{CO}_{2}$ (Fig. $3 c$ ). The $\mathrm{CO}_{2}$ threshold of RTN neurons was the same in intact ( $n=9$ neurons) and vagotomized $(n=13)$ rats (Fig. $3 a, b)$. The slope of the initial linear part of the response curve was also identical (Fig. $3 a-c$ ). The response of RTN neurons and PND to $\mathrm{CO}_{2}$ both saturated at high levels of $\mathrm{CO}_{2}$ (Fig. $3 c, f$ ).

Four of the $\mathrm{CO}_{2}$-sensitive cells recorded at steady state were labeled with biotinamide in vivo. In two cases, the labeling intensity was sufficient to reconstruct most of their dendritic structure (Fig. 4). Consistent with their location below the antidromic facial field potential, their cell bodies were located within $150 \mu \mathrm{m}$ of the ventral medullary surface below the caudal end of the facial motor nucleus. The examples shown in Figure 4 were from rats with intact vagus nerves. Note that PND was synchronized with ventilation (tracheal $\mathrm{CO}_{2}$ trace). One neuron had two periods of reduced discharge probability per respiratory cycle, and the other had three such periods.

\section{Respiratory patterns of RTN neurons} and their suppression by kynurenic acid The respiratory modulation of RTN neurons was examined in 30 neurons from 7 vagotomized rats and in 26 neurons from 15 rats with intact vagus nerves by constructing PND- or tracheal $\mathrm{CO}_{2}$ triggered histograms. e-exp CO2 was typically between 8 and 9\% (range of 7-10\%) at the time of acquisition of the perievent histograms. After visual inspection of the entire collection of histograms, 50 cells of 56 could be fitted to one of the four patterns illustrated in Figure 5. The rest could not be classified because their modulation was of too small an amplitude for reliable pattern recognition. The names of the patterns (e.g., early- ${ }^{-} /$post$\mathrm{I}^{-}$) are based on the assumption that the periods of reduced discharge probability correspond to periods when the cells are actively inhibited. The reasons for this choice will be reviewed in Discussion. Figure 5 depicts the four patterns and some of their most common variations. In a few cases, a perievent histogram obtained during a period of low e-exp $\mathrm{CO}_{2}$ is shown along with a second histogram of the same cell acquired during a period of high e-exp $\mathrm{CO}_{2}$ to reemphasize that, in all cases, the respiratory modulation increased with the intensity of the central respiratory drive as gauged by PND amplitude.

Patterns 1-3 were found in both vagotomized and intact rats. Pattern 1 was the most frequently observed (42\%). Pattern 2 was divided in two subtypes to reflect the observation that the inspiratory dip in the histograms was either incremental during the PND [defined as late-I inhibition) or decremental (defined as early-I inhibition). Pattern 4 was identified only in three cells, each recorded in separate rats with intact vagus nerves. The respiratory patterns were not sufficiently different between vagotomized and intact rats to gauge the influence of lung afferent inputs on the respiratory modulation of RTN neurons (Table 1 ). The respiratory pattern of a given neuron was invariant with time so long as the $\mathrm{CO}_{2}$ level was maintained constant. However, when $\mathrm{CO}_{2}$ was changed, the relative magnitude of the inhibitions could vary
Table 1. Respiratory patterns in vagotomized and intact rats

\begin{tabular}{llllll}
\hline & \multicolumn{5}{l}{ Number of neurons per pattern } \\
\cline { 2 - 6 } & Pattern 1 & Pattern 2 & Pattern 3 & Pattern 4 & Unclassified \\
\hline Vagus nucleus cut & 12 & 11 & 3 & 0 & 4 \\
Vagus nucleus intact & 9 & 4 & 8 & 3 & 2 \\
\hline
\end{tabular}

somewhat. For example, in cells 48.4 and 48.5 of Figure 4, post-I inhibition was clearly more prominent at higher levels of $\mathrm{CO}_{2}$. Usually, the initial pattern was not transformed into one of the other three. However, conversion of pattern 1 into pattern $2 \mathrm{a}$ at higher $\mathrm{CO}_{2}$ was clearly observed in two cases, probably attributable to increased cell inhibition during the late-expiratory (E2) phase (result not illustrated). These pattern changes were difficult to quantify and therefore not systematically investigated.

The broad-spectrum ionotropic glutamate receptor antagonist kynurenic acid eliminates PND and either silences ventrolateral medullary neurons with $\mathrm{ON}-\mathrm{OFF}$ discharges synchronized to the PND or blocks their phasic activity and response to $\mathrm{CO}_{2}$ (Mulkey at al., 2004). In four rats with intact vagus nerves, we were able to compare the discharge pattern of the same $\mathrm{CO}_{2}$ activated RTN neuron before and after intracerebroventricular treatment with KYN. Mere visual inspection of the recordings revealed that the discharge pattern of RTN neurons became strikingly regular after KYN administration (Fig. 6a1,a2). To quantify these changes, two types of analysis were made. First, perievent activity histograms triggered on tracheal $\mathrm{CO}_{2}$ were analyzed. After KYN, the discharge probability of the neurons became uniform across the ventilation cycle $(n=4)$ (Fig. 6b1,b2). However, because this outcome could also have been observed if KYN had uncoupled the CPG from vagal afferent inputs instead of inactivating the oscillator, we also compared the regularity of the dis- 

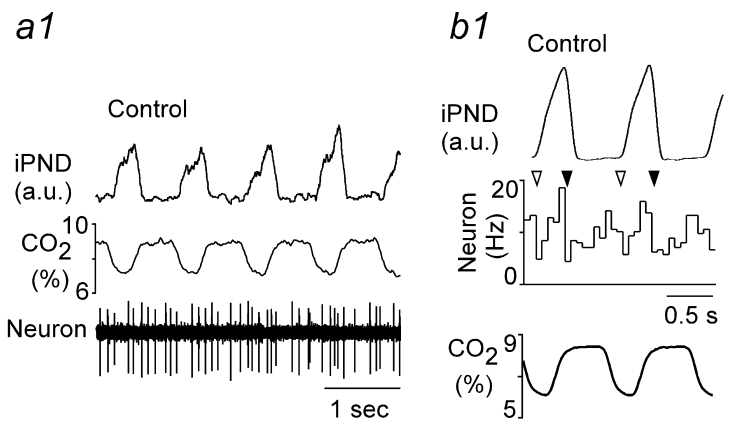

c1

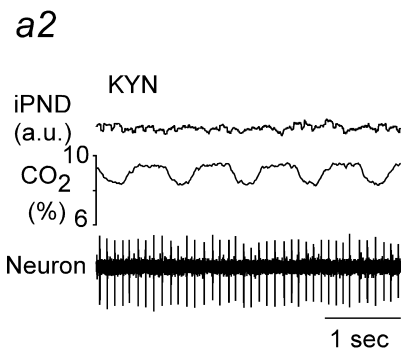

\section{$b 2$}

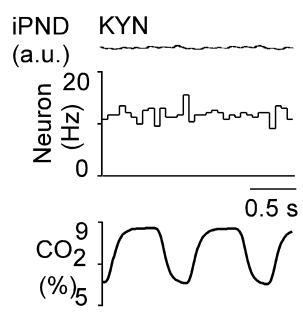

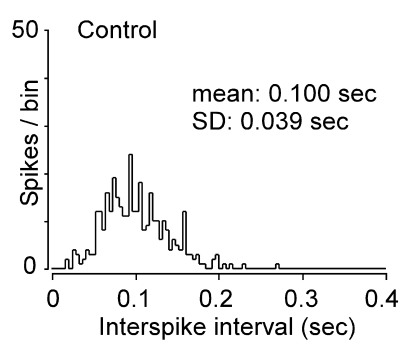

c2

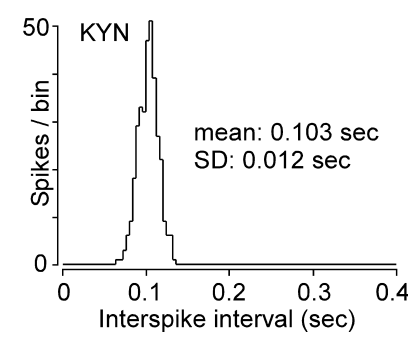

Figure 6. Kynurenic acid eliminate the respiratory modulation of RTN neurons. a1, a2, Excerpt of original recordings showing the discharge pattern of the same neuron before and after KYN administration (rat with intact vagus nerves). b1, b2, Perievent activity histograms of the same neuron before and after KYN. The histograms were triggered on tracheal $\mathrm{CO}_{2}$. $\mathbf{c 1}, \mathbf{C 2}$, Interspike interval distribution histogram for the same cell before and after KYN administration. The mean discharge rate of the cell was the same at the time when the histograms were made $(10 \mathrm{~Hz})$. a.u., Arbitrary units.

charge of the cells by means of interspike distribution histograms. These histograms were made using a period of the record when the cells discharged at the same average rate (mean $\pm \mathrm{SD}$ of interspike interval, $0.108 \pm 0.015 \mathrm{~Hz}$ before KYN vs $0.112 \pm$ $0.012 \mathrm{~Hz}$ after KYN; NS by paired $t$ test). KYN reduced the SD of the interspike histogram distributions threefold (from $0.049 \pm$ 0.004 to $0.017 \pm 0.002 \mathrm{~Hz} ; p<0.05$ by paired $t$ test), providing an objective measure of the regularization of the cells discharge pattern (Fig. 6c1,c2).

In summary, KYN eliminated all detectable respiratory-like fluctuations of the discharge pattern of RTN neurons, but the $\mathrm{CO}_{2}$ sensitivity of the cells persisted. Second, in the absence of input from the CPG, RTN neurons discharged in a tonic as opposed to bursting mode regardless of the $\mathrm{CO}_{2}$ level up to $10 \%$.

\section{Steady-state response of RTN neurons to hypercapnia after treatment with kynurenic acid}

The next experiments were designed to analyze quantitatively the sensitivity of RTN neurons to hypercapnia after KYN administration. This was accomplished by measuring the relationship between RTN neuronal firing rate and $\mathrm{CO}_{2}$ or $\mathrm{pHa}$ in 11 neurons from four KYN-treated rats. Measurements were made at steady state at the end of 3- to 4-min-long e-exp $\mathrm{CO}_{2}$ steps. e-exp $\mathrm{CO}_{2}$ was converted into $\mathrm{pHa}$ using the formula described in Materials and Methods (see data in Fig. 1).

The steady-state response of a typical RTN neuron to $\mathrm{CO}_{2}$ in a rat treated with kynurenic acid is shown in Figure $7 a$. Blood pressure was characteristically low attributable to the migration of KYN to the spinal cord and elimination of sympathetic tone (Sun et al., 1988). Note that the RTN cell was silent below 5\% $\mathrm{CO}_{2}$, increasingly active above this level, and discharged with extreme regularity even at high levels of $\mathrm{CO}_{2}$ (Fig. 7b). Its steadystate discharge appeared linearly related to both e-exp $\mathrm{CO}_{2}$ and arterial pH (Fig. $7 c, d)$. Similar results were obtained in 11 neurons in four rats (Fig. 7e,f). At the population level, the response of RTN neurons also appeared approximately linear, i.e., displayed no apparent saturation at high $\mathrm{CO}_{2}$, unlike the response of animals without KYN (compare Figs. $3 c, 7 g$ ). The mean $\mathrm{CO}_{2}$ threshold of RTN neurons was the same with or without kynurenic acid (4.5\%) (compare Figs. $3 c, 7 g$ ), but the average slope of the $\mathrm{CO}_{2}$ response curves was only $1.7 \pm 0.2 \mathrm{~Hz} / 1 \%$ $\mathrm{CO}_{2}$ in KYN-treated rats (11 neurons). This value was significantly smaller than the $\mathrm{CO}_{2}$ sensitivity of RTN neurons measured in their linear range below PND threshold in control (KYN-free) rats $\left(3.2 \pm 0.3 \mathrm{~Hz} / 1 \% \mathrm{CO}_{2}\right.$ for 18 cells in vagotomized or intact rats; $p<0.013$, Mann-Whitney rank sum test). KYN may reduce the $\mathrm{CO}_{2}$ sensitivity of RTN neurons in part by eliminating residual inputs from peripheral chemoreceptors that could have persisted despite the hyperoxia (Mulkey et al., 2004).

In the presence of $\mathrm{KYN}$, the mean arterial $\mathrm{pH}$ at threshold was $7.48 \pm 0.015$ based on the $x$-axis intersect of 11 individual linear regressions of the type shown in Figure $7, d$ and $f$. The mean sensitivity to arterial $\mathrm{pH}$ calculated from the slopes of the same 11 regression lines was $3.9 \pm 0.4 \mathrm{~Hz} / 0.1 \mathrm{pH}$ unit. The mean $\mathrm{pH}$ sensitivity was slightly higher when calculated by binning the individual data points from all the cells as indicated in Figure $7 h$.

\section{Sensitivity of RTN neurons to $\mathrm{pH}$ in slices}

The experiments were designed to determine the $\mathrm{pH}$ sensitivity and $\mathrm{pH}$ threshold of RTN neurons in thin coronal slices in which synaptic inputs are generally reduced and inputs from other segments of the VRC are absent by definition (Fig. $8 a$ ). Cells had to be active at $\mathrm{pH} 7.3$ to be studied further. The population contained $18 \mathrm{pH}$-sensitive and $10 \mathrm{pH}$-insensitive neurons.

We focused on the narrow range of $\mathrm{pH}$ that is relevant for the in vivo situation (7.55-7.2) and examined the effect of temperature on the response of the cells to $\mathrm{pH}$ (Fig. $8 b, c)$. The response of RTN neurons to acidification was linear down to $\mathrm{pH} 7.2$ but deviated from a straight line at more acidic $\mathrm{pH}$, especially at elevated temperature (Fig. $8 d$ ). Of note, temperature selectively increased the dynamic range of the $\mathrm{pH}$ response of acid-sensitive RTN neurons but had no effect on their pH threshold (Fig. 8b-f). Because the relationship between neuronal discharge rate and $\mathrm{pH}$ was linear at the population level between $\mathrm{pH} 7.55$ and 7.2, the $\mathrm{pH}$ sensitivity of each cell was calculated from the slope of a linear regression through the data points corresponding to this $\mathrm{pH}$ range. We deliberately avoided using the previously defined "chemosensitivity index" to quantify the $\mathrm{pH}$ sensitivity of RTN neurons because this index measures a percentage change in rate for a $0.2 \mathrm{pH}$ unit change (Richerson et al., 2001). This index cannot appropriately describe a linear relationship because it varies with the reference $\mathrm{pH}$ and tends toward infinity as the reference $\mathrm{pH}$ nears the firing threshold of the cell (here 7.55). $\mathrm{pH}$ sensitivity was determined for 12 cells recorded at $23^{\circ} \mathrm{C}$ and 12 cells recorded at $35^{\circ} \mathrm{C}$. The sample included six cells that were studied at both temperatures (examples in Fig. $8 b, c$ ). The $\mathrm{pH}$ sensitivity of RTN neurons was $0.59 \pm 0.1 \mathrm{~Hz} / 0.1 \mathrm{pH}$ unit at $23^{\circ} \mathrm{C}$ and $1.68 \pm$ 
0.2 at $35^{\circ} \mathrm{C}$ (range of $0.55-2.84 ; n=12$ ), a highly significant effect ( $p<0.0001$ by unpaired $t$ test). A two-point determination of the $Q_{10}$ yielded a value of 2.4 , i.e., $\mathrm{pH}$ sensitivity doubled every $7.9^{\circ} \mathrm{C}$. In contrast, the $\mathrm{pH}$ threshold was virtually independent of temperature because, regardless of the temperature, the cells were silent at $\mathrm{pH} 7.55$, and all but one were active at $\mathrm{pH} 7.4$ (Fig. 8e,f). This combination of properties clearly distinguished $\mathrm{pH}$ sensitive neurons from other RTN neurons with ongoing activity. The latter increased their firing rate as markedly as the $\mathrm{pH}$ sensitive ones when temperature was elevated but were equally insensitive to $\mathrm{pH}$ at both temperatures tested $(n=10)$ (Fig. $8 g$ ).

Based on a $Q_{10}$ of 2.4 , the extrapolated discharge rate of RTN neurons in vitro at $37.5^{\circ} \mathrm{C}$ should be $125 \%$ of that observed at $35^{\circ} \mathrm{C}$ or $2.1 \pm 0.25 \mathrm{~Hz} / 0.1 \mathrm{pH}$ unit $(n=12)$. This value was significantly smaller than the in vivo sensitivity of $\mathrm{CO}_{2}$ responsive $\mathrm{RTN}$ neurons measured against arterial $\mathrm{pH}$ in halothane-anesthetized rats in the presence of KYN $(3.9 \pm 0.42$ $\mathrm{Hz} / 0.1 \mathrm{pHa}$ unit; $n=11 ; p=0.0013$ by $t$ test), but the ranges overlapped substantially $(0.7-3.6 \mathrm{~Hz} / 0.1 \mathrm{pH}$ unit in vitro vs $1.8-$ $6.7 \mathrm{~Hz}$ in vivo).

In a population of 317 active neurons located below the caudal end of the facial motor nucleus (including the 28 cells of this study and all cells from published and unpublished work), we never encountered cells with ON-OFF rhythmic bursts (i.e., high-frequency action potential discharge with intervening quiescent periods of relatively constant duration). We did find four neurons in this group that displayed a modest slow firing rhythm, but, in those cases, there was no high-frequency discharge or distinct ON-OFF pattern, the firing frequency was uniformly low, and the response was transient.

\section{Discussion}

To summarize, when RTN neurons are disconnected from the $\mathrm{CPG}$ in vivo or in vitro, their $\mathrm{pH}$ response is linear and they discharge tonically. In vivo, these cells receive an inhibitory feedback from the CPG that causes their discharge to become respiratory modulated and to saturate at high levels of $\mathrm{CO}_{2}$. More than $40 \%$ of RTN cells have a respiratory modulation reminiscent of the neonate pfRG, suggesting that pfRG cells are a subset of RTN neurons recorded under different experimental conditions. We conclude that, in the adult, RTN neurons are neither intrinsic pacemakers nor rhythmogenic but central chemoreceptors subject to a feedback control by the CPG.

\section{Experimental limitations: comparison with previous results}

The combination of hyperoxia and halothane produced a high $\mathrm{CO}_{2}$ threshold for CPG activity in our preparation (6.5\%). Possible reasons include the fact that peripheral chemoreceptors make little or no contribution to the effects of hypercapnia in our model (Mulkey et al., 2004) and a reduction in CPG neuron excitability attributable to TASK (TWIK-related acid-sensitive $\mathrm{K}^{+}$channels) channel activation by halothane (Bayliss et al., 2001).

RTN neurons recorded presently had a similar location, structure, dynamic range, and $\mathrm{CO}_{2}$ threshold as reported previously (Mulkey et al., 2004). We confirm that RTN neurons lack respiratory modulation over most of their dynamic range and that most cells retain a finite probability of discharge at any period of the respiratory cycle, unlike typical CPG neurons under the same conditions (Guyenet and Wang, 2001). However, our previous study of RTN neurons underestimated RTN respiratory modulation for three reasons. Respiratory modulation was previously gauged using the $\eta^{2}$ index (Orem and Dick, 1983), a less sensitive a

C

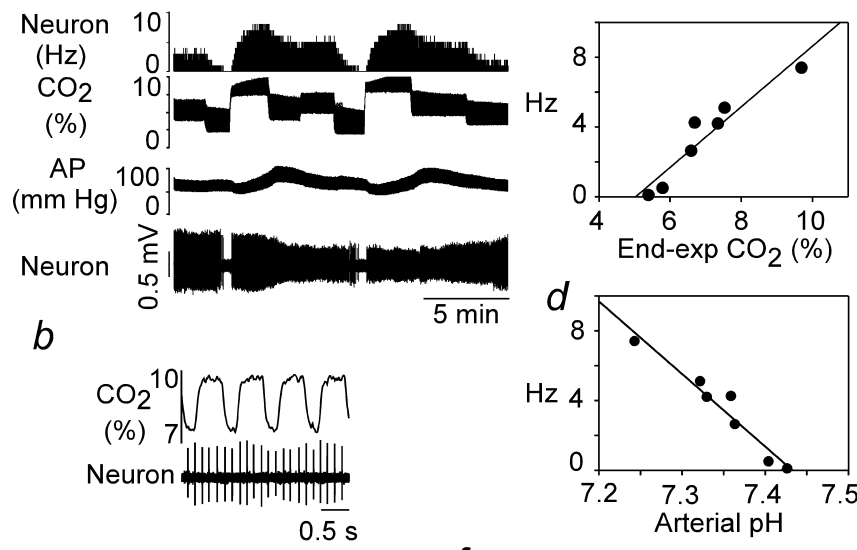

e

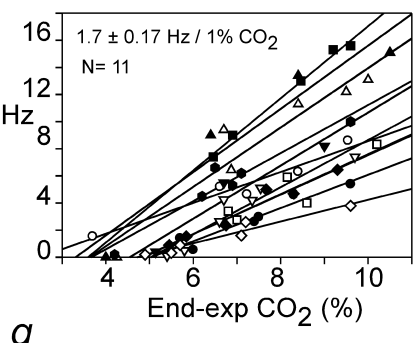

$f$
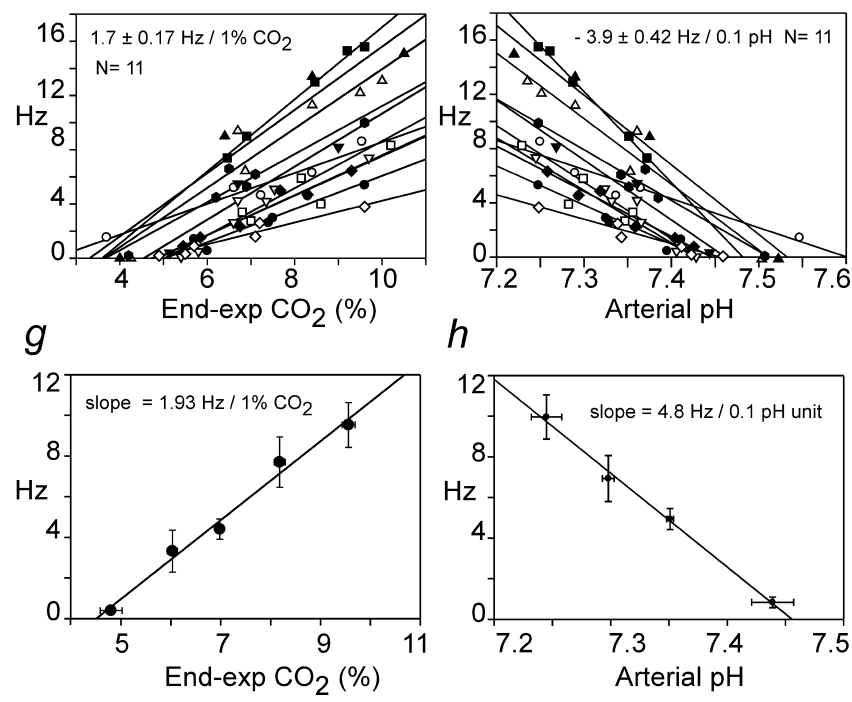

h

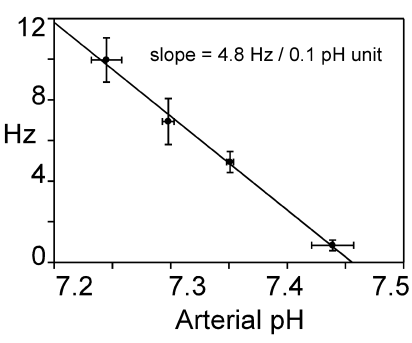

Figure 7. Response of RTN neurons to hypercapnia at steady state in rats treated with kynurenic acid. a, Example of original recording traces. Arterial pressure (AP) is low attributable to central sympatholytic action of KYN. $\boldsymbol{b}$, Same cell at expanded time scale to illustrate regularity of discharges. $c$, Plot of discharge rate of the cell versus end-expiratory $\mathrm{CO}_{2}$ at steady state. $\boldsymbol{d}$, Replot of the same data after conversion of end-expiratory $\mathrm{CO}_{2}$ values into $\mathrm{pHa}$ values using the relationship shown in Figure 1c. e, Relationship between discharge rate and e-exp $\mathrm{CO}_{2}$ for the 11 cells recorded. Individual regression lines are shown, and the number shown above the plots represent the mean $\pm S E$ of their individually determined slopes. $f$, Relationship between discharge rate and calculated pHa for the 11 cells recorded. Individual regression lines are shown, and the number shown above the plots represent the mean \pm SE of the individually determined slopes. $\boldsymbol{g}$, Relationship between discharge rate and e-exp $\mathrm{CO}_{2}$ for the 11 cells. The data were analyzed as in Figure $3 a-c$, i.e., individual points from all cells (data from $\boldsymbol{e}$ ) were regrouped into five bins according to the $\mathrm{CO}_{2}$ level at which each determination was made $(<5.5,5-5-6.5,6.5-7.5,7.5-8.5,>8.5 \%)$, and the values were averaged within these bins (mean \pm SE for both axis shown). $\boldsymbol{h}$, Relationship between discharge rate and $\mathrm{pHa}$. The data were processed as in $\boldsymbol{g}$ except that only four bins were used ( $\mathrm{pH}<7.275,7.275-7.325,7.325-$ $375,>7.375)$. In $\boldsymbol{g}$ and $\boldsymbol{h}$, the slope of the regression line through the four or five resulting data points is shown.

index than perievent histograms. We previously explored lower levels of $\mathrm{CO}_{2}$ at which respiratory modulation is modest. Finally, hypercapnia was not usually studied under steady-state conditions.

The respiratory modulation of RTN neurons is attributable to inputs from the CPG that are probably inhibitory

At high e-exp $\mathrm{CO}_{2}$, virtually all RTN neurons exhibited some respiratory modulation. Modulation was absent below PND threshold and increased with increasing PND intensity. In vagot- 
a

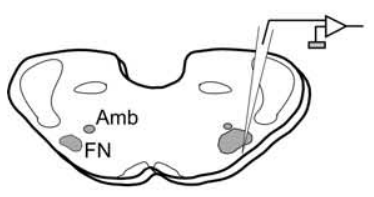

$d$

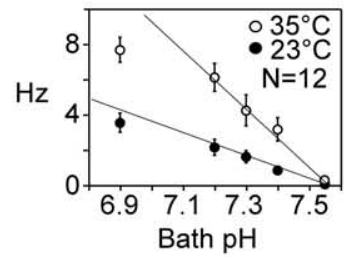

b

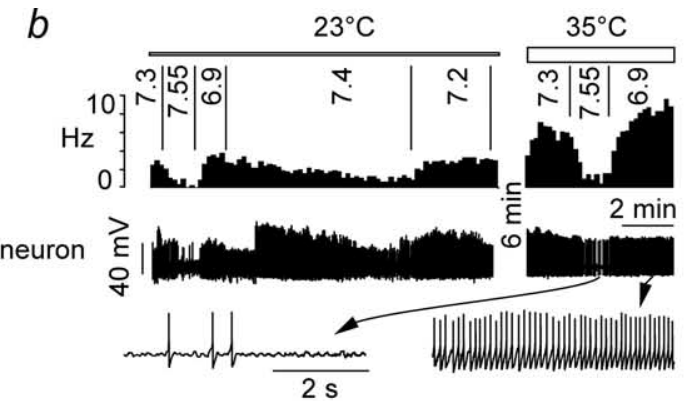

e

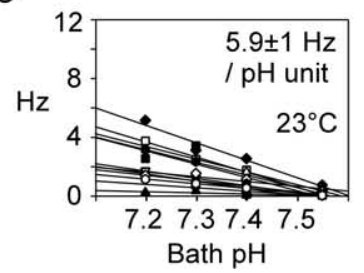

c

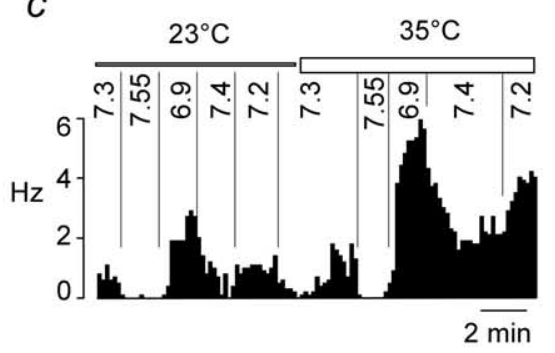

Figure 8. Response of RTN neurons to acidification in vitro: effect of temperature. $\boldsymbol{a}$, Experimental design. Neurons were recorded within $200 \mu \mathrm{m}$ of the ventral medullary surface below the caudal end of the facial motor nucleus (FN). The facial motor nucleus was identified by retrograde labeling with Fluoro-Gold (Amb, nucleus ambiguus). $\boldsymbol{b}$, Example of one RTN neuron exposed to various levels of bath $\mathrm{pH}$ at 23 and $35^{\circ} \mathrm{C}$ (top trace, integrated rate histogram, 10 s bins; bottom trace and excerpts, original recording at 2 different time scales). $c$, Second example of an RTN neuron studied at both temperatures. $\boldsymbol{d}$, Relationship between discharge rate and bath pH for 12 neurons recorded at $23^{\circ} \mathrm{C}$ and 12 neurons recorded at $35^{\circ} \mathrm{C}$, six being recorded at both temperatures ( $p<$ 0.001 by ANOVA for effect of temperature). The regression lines through the data points from pH 7.2-7.55 are shown to emphasize the deviation from linearity at very acidic pH (6.9). $\boldsymbol{e}, \boldsymbol{f}$, Relationship between discharge rate and bath $\mathrm{pH}$ (range of 7.2-7.55) for each of the 12 cells. Individually determined regression lines are shown, and the mean \pm SE of their slope is indicated. $\boldsymbol{g}$, Relationship between discharge rate and $\mathrm{pH}$ for 10 RTN neurons that were considered $\mathrm{pH}$ insensitive.

omized rats, RTN neurons were synchronized with PND but not with the ventilation cycle. This evidence demonstrates that the respiratory modulation of RTN neurons was caused by synaptic inputs from CPG neurons and did not merely result from oligosynaptic inputs from vagal or somatic afferents active in-phase with the ventilation cycle or from within-breath fluctuations in blood $\mathrm{pCO}_{2}$ (Eldridge and Millhorn, 1986).

We attribute the respiratory modulation of RTN neurons to inhibitory inputs for two reasons. First, the relationship between $\mathrm{pCO}_{2}$ and firing rate deviated downward from linearity only when the cells started to receive significant phasic inputs from the CPG. Second, no response saturation could be detected when the CPG was silenced by kynurenic acid.

The four identified respiratory patterns qualify as phase spanning because the changes in discharge probability were not locked solely to inspiration, post-inspiration, or late-expiration (Feldman, 1987). The proposed classification of these patterns leaves room for the possibility that every RTN neuron receives inhibitory inputs from early-I (or late-I), post-I, and E2 neurons, albeit in varying proportion. That individual RTN neurons seem capable of exhibiting every possible permutation between these three inputs suggests that, at the population level, RTN neurons may receive equal amounts of inhibition from early-I, post-I, and E2 neurons. Eventually, intracellular recordings of RTN neurons will be needed to confirm our interpretation.

The cat's RTN contains hypercapnia-sensitive neurons with axonal projections comparable with the rat's. Their discharges are more strongly phase locked to PND and typically synchronized with inspiration or expiration rather than phase spanning or biphasic (Connelly et al., 1990; Nattie et al., 1993; Bodineau et al., 2000). However, respiratory patterns can be species or anesthetic related, and, although the chemosensitivity of cat's RTN neurons is untested, a functional homology between rat's and cat's RTN neurons remains plausible (for further discussion of the comparative anatomy of RTN, see Weston et al., 2004).

\section{RTN neurons respond linearly to $\mathrm{pH}$ in slices and in vivo after CPG blockade}

Temperature greatly increased the dynamic range of the $\mathrm{pH}$ response of RTN neurons in vitro without influencing their $\mathrm{pH}$ threshold. At elevated temperature, the effect of $\mathrm{pH}$ on RTN neurons was robust, cell specific, and linear within the physiological range (7.2-7.5). Given a $Q_{10}$ of 2.4, the extrapolated $\mathrm{pH}$ sensitivity at $37.5^{\circ} \mathrm{C}$ in slices was $\sim 2.2 \mathrm{~Hz} / 0.1 \mathrm{pH}$ unit, a value comparable with the most $\mathrm{pH}$-responsive neurons previously recorded in vitro (Putnam et al., 2004; Ritucci et al., 2005). Of greater importance perhaps, the $\mathrm{pH}$ threshold of the cells was essentially the same in vitro and in vivo $(\mathrm{pH} 7.5)$, and their $\mathrm{pH}$ sensitivity in vitro was close to that measured in vivo under conditions of reduced synaptic activity, i.e., KYN treatment (2.2 vs $3.9 \mathrm{~Hz} / 0.1 \mathrm{pH}$ unit). The modestly lower $\mathrm{pH}$ sensitivity of the neurons in vitro $(-43 \%)$ could be attributable to the immaturity of the cells, a slight difference in the sampled population, the incomplete reduction of synaptic inputs by KYN in vivo, or a direct stimulatory effect of halothane. Finally, the changes in arterial $\mathrm{pH}$ may underestimate the changes in brain extracellular pH during hypercapnia (Cragg et al., 1977; Eldridge et al., 1984; Kintner et al., 1999; Li and Nattie, 2002) because brain extracellular fluid (ECF), being protein poor unlike blood, may behave more like a bicarbonate buffer (Boron, 2003; Richerson and Boron, 2003).

Final proof that the chemosensitivity of RTN neurons is purely an intrinsic property is not available (Guyenet et al., 2005; Richerson et al., 2005). The notion rests on the resistance of their $\mathrm{pH}$ sensitivity to ATP and glutamate receptor blockade (Mulkey et al., 2004; this study) and the presence of a $\mathrm{pH}$-sensitive potassium current elicited by alkalization in the presence of TTX (Mulkey et al., 2004). These neurons could conceivably be also responding to unknown paracrine signals released from surrounding pH-sensitive cells (Guyenet et al., 2005; Richerson et al., 2005). 


\section{Role of the inhibitory inputs from the CPG to RTN neurons}

Because RTN neurons have properties consistent with central chemoreceptors, we propose that their CPG inputs represent a feedback (supplemental Fig. S1 $a$, available at www.jneurosci.org as supplemental material). The present evidence suggests that this feedback occurs in the form of inputs from early-I, late-I, post-I, and E2 neurons (supplemental Fig. S1 b, available at www. jneurosci.org as supplemental material), inhibitory neurons that are central to the genesis of the respiratory drive (Rybak et al., 2004). The model accounts for the often described curvilinear response between arterial $\mathrm{pCO}_{2}$ or $\mathrm{ECF} \mathrm{pH}$ and the inspiratory motor outflow (Eldridge et al., 1984, 1985; present study) because the inhibitory inputs from the CPG to RTN neurons increase gradually in intensity along with the central respiratory drive. Eventually, competition between the intrinsic stimulatory effect of pH on RTN neurons and the CPG feedback should cause these cells to reach a maximum firing rate at high $\mathrm{pCO}_{2}$ as is observed. At equilibrium, the saturation of the discharge of the chemoreceptors should in turn produce a saturation of the inspiratory motor outflow.

The model assumes that RTN neurons are the major source of chemoreceptor drive for inspiratory activity. Although RTN undoubtedly contributes to inspiratory activity (Nattie, 2001; Feldman et al., 2003; Mulkey et al., 2004; Putnam et al., 2004), it remains possible that central chemosensitivity also involves other brainstem sites (Feldman et al., 2003; Hodges et al., 2004; Putnam et al., 2004; Richerson, 2004; Richerson et al., 2005). Considering that the brainstem neurons targeted by RTN chemoreceptors are still unidentified, other interpretations of the role of RTN neurons should be considered. For instance, RTN neurons may also regulate the parasympathetic bronchomotor outflow, which is also morphine resistant, activated by central chemoreceptors, and respiratory modulated (Perez Fontan and Velloff, 1997; Perez Fontan et al., 1998). Subsets of RTN neurons may also regulate expiratory muscles (Janczewski et al., 2002). These roles could be performed by different albeit equally chemosensitive cells, a possible explanation for the variety of central respiratory patterns displayed by RTN neurons.

\section{Are the chemosensitive neurons of RTN the adult form of neonate pfRG neurons?}

Adult RTN and neonate pfRG pre-inspiratory (pre-I) neurons have a similar location (Onimaru and Homma 2003; Mulkey et al., 2004). Some pre-I pfRG neurons are also mildly activated by acidification in vitro, and, like many RTN neurons in vivo, they are relatively insensitive to morphine and their respiratory pattern is biphasic (Takeda et al., 2001; Janczewski et al., 2002; Mulkey et al., 2004). The main respiratory pattern of RTN neurons (early-I/post-I inhibition; $42 \%$ of cells with an identifiable pattern) (Fig. 4) could be a match for pfRG neurons if one defines the $\mathrm{E} 2$ phase in vivo as pre-inspiration. One would also have to assume that the twin peri-inspiratory bursts of pfRG neurons are attributable to the relaxation during the E2 and late-I phases of inhibitory synaptic inputs that oppose the intrinsic chemosensitive drive of the cells at all other times of the cycle. This interpretation is compatible with our evidence that RTN neurons discharge tonically when disconnected from the CPG by coronal tissue sectioning, but it needs to be reconciled with the fact that many pfRG neurons keep bursting in the en bloc preparation under conditions presumed to have attenuated calciummediated transmitter release (Onimaru et al., 1995). On balance, it seems that adult RTN and neonate pfRG neurons share enough characteristics to suggest that they might represent the same or at least overlapping neuronal populations at two stages of development.

One objection to this interpretation is that many of the pre-I cells identified in the early neonate rat (P1-P2) reside under the lateral half of the facial motor nucleus (Onimaru and Homma, 2003) whereas the adult RTN lies below the medial and caudal edge of this nucleus (supplemental Fig. S2, available at www. jneurosci.org as supplemental material). This apparent discrepancy raises the question of whether bursting pfRG neurons of the type identified by Onimaru and Homma (2003) were missed in the present study because they reside in a location that we did not sample. We do not think that this is very likely for the following reason. As illustrated in supplemental Figure 2 (available at www.jneurosci.org as supplemental material), there are virtually no glutamatergic neurons [i.e., neurons expressing vesicular glutamate transporter-2 (VGLUT2)] or GABAergic neurons under the lateral half of the facial motor nucleus in the adult. In contrast, this region is lined with a compact layer of VGLUT2expressing neurons in P1-P2 neonates (Weston et al., 2004, their Fig. 2). The simplest explanation is that the VGLUT2-expressing cells located under the lateral half of the facial motor nucleus in $\mathrm{P} 1-\mathrm{P} 2$ rats are the pfRG neurons and that, in adults, these cells reside more medially relative to the facial motor nucleus because of the non-isometric growth of the overlying region. Another possibility is that the parafacial pre-I bursters of the neonate are evolutionary remnants of an archaic vertebrate expiratory rhythm generator (Mellen et al., 2003) that disappears early after birth.

\section{Conclusions}

From postnatal day 7 on, the properties of RTN cells are consistent with central chemoreceptors but inconsistent with intrinsically bursting rhythmogenic neurons. RTN neurons receive periodic inhibitory inputs from the CPG that may represent a feedback regulation of central chemoreception.

\section{References}

Alheid GF, Gray PA, Jiang MC, Feldman JL, McCrimmon DR (2002) Parvalbumin in respiratory neurons of the ventrolateral medulla of the adult rat. J Neurocytol 31:693-717.

Bayliss DA, Talley EM, Sirois JE, Lei QB (2001) TASK-1 is a highly modulated $\mathrm{pH}$-sensitive "leak" $\mathrm{K}^{+}$channel expressed in brainstem respiratory neurons. Respir Physiol 129:159-174.

Bodineau L, Frugiere A, Marlot D, Wallois F (2000) Effect of hypoxia on the activity of respiratory and non-respiratory modulated retrotrapezoid neurons of the cat. Auton Neurosci 86:70-77.

Boron WF (2003) Acid-base physiology. In: Medical physiology (Boron WF, Boulpaep EL, eds), pp 633-653. Philadelphia: Saunders.

Brown DL, Guyenet PG (1985) Electrophysiological study of cardiovascular neurons in the rostral ventrolateral medulla in rats. Circ Res 56:359-369.

Connelly CA, Ellenberger HH, Feldman JL (1989) Are there serotonergic projections from raphe and retrotrapezoid nuclei to the ventral respiratory group in the rat? Neurosci Lett 105:34-40.

Connelly CA, Ellenberger HH, Feldman JL (1990) Respiratory activity in retrotrapezoid nucleus in cat. Am J Physiol 258:L33-L44.

Cragg P, Patterson L, Purves MJ (1977) The $\mathrm{pH}$ of brain extracellular fluid in the cat. J Physiol (Lond) 272:137-166.

Cream C, Li A, Nattie E (2002) The retrotrapezoid nucleus (RTN): local cytoarchitecture and afferent connections. Respir Physiol Neurobiol 130:121-137.

Eldridge FL, Millhorn DE (1986) Oscillation, gating and memory. In: Handbook of physiology, Sec 3, The respiratory system, Vol 2, Control of breathing, Pt 1 (Fishman AP, Cherniack NS, Widdicombe JG, eds), pp 93-114. Bethesda, MD: American Physiological Society.

Eldridge FL, Kiley JP, Millhorn DE (1984) Respiratory effects of carbon dioxide-induced changes of medullary extracellular fluid $\mathrm{pH}$ in cats. J Physiol (Lond) 355:177-189. 
Eldridge FL, Kiley JP, Millhorn DE (1985) Respiratory responses to medullary hydrogen ion changes in cats: different effects of respiratory and metabolic acidoses. J Physiol (Lond) 358:285-297.

Feldman JL (1987) Neurophysiology of breathing in mammals. In: Handbook of physiology: the nervous system, Vol IV (Bloom FE, ed), pp 463524. Bethesda, MD: American Physiological Society.

Feldman JL, Mitchell GS, Nattie EE (2003) Breathing: rhythmicity, plasticity, chemosensitivity. Annu Rev Neurosci 26:239-266.

Fitzgerald RS, Lahiri S (1991) Reflex responses to chemoreceptor stimulation. In: Handbook of physiology, pp 313-362. Bethesda, MD: American Physiological Society.

Fukuda Y, Tojima H, Tanaka K, Chiba T (1993) Respiratory suppression by focal cooling of ventral medullary surface in anesthetized rats-functional and neuroanatomical correlate. Neurosci Lett 153:177-180.

Guyenet PG, Wang H (2001) Pre-Botzinger neurons with preinspiratory discharges "in vivo" express NK1 receptors in the rat. J Neurophysiol 86:438-446.

Guyenet PG, Stornetta RL, Bayliss DA, Mulkey DK (2005) Retrotrapezoid nucleus: a litmus test for the identification of central chemoreceptors. Exp Physiol 90:247-257.

Hodges MR, Martino P, Davis S, Opansky C, Pan LG, Forster HV (2004) Effects on breathing of focal acidosis at multiple medullary raphe sites in awake goats. J Appl Physiol 97:2303-2309.

Janczewski WA, Onimaru H, Homma I, Feldman JL (2002) Opioidresistant respiratory pathway from the preinspiratory neurones to abdominal muscles: in vivo and in vitro study in the newborn rat. J Physiol (Lond) 545:1017-1026.

Kintner DB, Anderson ME, Sailor KA, Dienel G, Fitzpatrick JH Jr, Gilboe DD (1999) In vivo microdialysis of 2-deoxyglucose 6-phosphate into brain: a novel method for the measurement of interstitial $\mathrm{pH}$ using 31P-NMR. J Neurochem 72:405-412.

Koshiya N, Guyenet PG (1996) Tonic sympathetic chemoreflex after blockade of respiratory rhythmogenesis in the rat. J Physiol (Lond) 491:859-869.

Leong SK, Ling EA (1990) Labeling neurons with fluorescent dyes administered via intravenous, subcutaneous or intraperitoneal route. J Neurosci Methods 32:15-23.

Li A, Nattie E (2002) CO2 dialysis in one chemoreceptor site, the RTN: stimulus intensity and sensitivity in the awake rat. Respir Physiol Neurobiol 133:11-22.

Mellen NM, Janczewski WA, Bocchiaro CM, Feldman JL (2003) Opioidinduced quantal slowing reveals dual networks for respiratory rhythm generation. Neuron 37:369-385.

Mulkey DK, Stornetta RL, Weston MC, Simmons JR, Parker A, Bayliss DA, Guyenet PG (2004) Respiratory control by ventral surface chemoreceptor neurons in rats. Nat Neurosci 7:1360-1369.

Nattie E, Li A (2000) Muscimol dialysis in the retrotrapezoid nucleus region inhibits breathing in the awake rat. J Appl Physiol 89:153-162.

Nattie EE (2001) Central chemosensitivity, sleep, and wakefulness. Respir Physiol 129:257-268.

Nattie EE, Fung ML, Li A, St. John WM (1993) Responses of respiratory modulated and tonic units in the retrotrapezoid nucleus to $\mathrm{CO} 2$. Respir Physiol 94:35-50.

Onimaru H, Homma I (2003) A novel functional neuron group for respiratory rhythm generation in the ventral medulla. J Neurosci 23:1478-1486.

Onimaru H, Arata A, Homma I (1995) Intrinsic burst generation of preinspiratory neurons in the medulla of brainstem-spinal cord preparations isolated from newborn rats. Exp Brain Res 106:57-68.

Orem J, Dick T (1983) Consistency and signal strength of respiratory neuronal activity. J Neurophysiol 50:1098-1107.

Paxinos G, Watson C (1998) The rat brain in stereotaxic coordinates. San Diego: Academic.

Perez Fontan JJ, Velloff CR (1997) Neuroanatomic organization of the parasympathetic bronchomotor system in developing sheep. Am J Physiol 273:R121-R133.

Perez Fontan JJ, Kinloch LP, Donnelly DF (1998) Integration of bronchomotor and ventilatory responses to chemoreceptor stimulation in developing sheep. Respir Physiol 111:1-13.

Putnam RW, Filosa JA, Ritucci NA (2004) Cellular mechanisms involved in $\mathrm{CO}_{2}$ and acid signaling in chemosensitive neurons. Am J Physiol Cell Physiol 287:C1493-C1526.

Richerson GB (1995) Response to CO2 of neurons in the rostral ventral medulla in vitro. J Neurophysiol 73:933-944.

Richerson GB (2004) Serotonergic neurons as carbon dioxide sensors that maintain pH homeostasis. Nat Rev Neurosci 5:449-461.

Richerson GB, Boron WF (2003) Control of ventilation. In: Medical physiology (Boron WF, Boulpaep EL, eds), pp 712-734. Philadelphia: Saunders.

Richerson GB, Wang WG, Tiwari J, Bradley SR (2001) Chemosensitivity of serotonergic neurons in the rostral ventral medulla. Resp Physiol 129:175-189.

Richerson GB, Wang W, Hodges MR, Dohle CI, Diez-Sampedro A (2005) Homing in on the specific phenotype(s) of central respiratory chemoreceptors. Exp Physiol 90:259-266.

Ritucci NA, Erlichman JS, Leiter JC, Putnam RW (2005) The response of membrane potential $(\mathrm{Vm})$ and intracellular $\mathrm{pH}(\mathrm{pHi})$ to hypercapnia in neurons and astrocytes from rat retrotrapezoid nucleus (RTN). Am J Physiol Regul Integr Comp Physiol 289:R851-R861.

Rybak IA, Shevtsova NA, Paton JF, Dick TE, St. John WM, Morschel M, Dutschmann M (2004) Modeling the ponto-medullary respiratory network. Resp Physiol Neurobiol 143:307-319.

Smith JC, Morrison DE, Ellenberger HH, Otto MR, Feldman JL (1989) Brainstem projections to the major respiratory neuron populations in the medulla of the cat. J Comp Neurol 281:69-96.

Sun MK, Hackett JT, Guyenet PG (1988) Sympathoexcitatory neurons of rostral ventrolateral medulla exhibit pacemaker properties in the presence of a glutamate-receptor antagonist. Brain Res 438:23-40.

Takeda S, Eriksson LI, Yamamoto Y, Joensen H, Onimaru H, Lindahl SGE (2001) Opioid action on respiratory neuron activity of the isolated respiratory network in newborn rat. Anesthesiology 95:740-749.

Weston MC, Stornetta RL, Guyenet PG (2004) Glutamatergic neuronal projections from the marginal layer of the rostral ventral medulla to the respiratory centers in rats. J Comp Neurol 473:73-85. 